\title{
Carbapenem Resistance Mechanisms and Molecular Epidemiology of Acinetobacter spp. from Four Hospitals in Seoul and Gyeonggi Province in 2006
}

\author{
Kyoung Ho Roh', Chang-Ki Kim², Jong Hwa Yum ${ }^{3}$, Dongeun Yong ${ }^{4,5}$, Seok Hoon Jeong, ${ }^{4,5}$ \\ Chae Seung Lim', Chang Kyu Lee', Yunjung Cho', Kyungwon Lee ${ }^{4,5}$, Yunsop Chong, \\ ${ }^{1}$ Department of Laboratory Medicine, Korea University College of Medicine, \\ ${ }^{2}$ Korean Institute of Tuberculosis, Seoul, ${ }^{3}$ Department of Clinical Laboratory Science, Dongeui University, Busan, \\ ${ }^{4}$ Department of Laboratory Medicine and ${ }^{5}$ Research Institute of Bacterial Resistance, \\ Yonsei University College of Medicine, Seoul, Korea
}

Background: Increasing numbers of Acinetobacter spp. resistant to multiple drugs, including carbapenem, has been a serious problem. The aims of this study were to determine carbapenem resistance patterns and mechanisms, as well as to study the molecular epidemiology of Acinetobacter spp.

Methods: Clinical isolates of Acinetobacter spp. were collected from May to November in 2006. Antimicrobial susceptibility testing was performed using CLSI disk diffusion and agar dilution methods. Metallo- $\beta$ lactamase- and OXA carbapenemase-producing isolates were detected by PCR. Carbapenem resistance and hydrolytic activities were compared according to OXA type and presence of ISAba1. Pulsed-field gel electrophoresis (PFGE) was performed to determine the epidemiologic features.

Results: The imipenem non-susceptible rates were variable from $10 \%$ to $67 \%$. Among 151 isolates carrying blaoxA-51-like, 75 isolates carried both blaoxA-51-like and ISAba1, and 25 isolates had both blaoxA-51-like, blaoxA-23-like, and ISAba1. Carbapenem MICs of both blaoXA-51-like and ISAba1-carrying isolates were higher than those with blaoxA-51-like only. Carbapenem MICs of blaoxA-23-like-carrying isolates were higher than those with both bla OXA-51-like and ISAba1. Both bla OXA-51-like and ISAba1-carrying isolates and blaoxA-51-like, blaoxA-23-like, and ISAba1-carrying isolates demonstrated higher hydrolysis activities in oxacillin and carbapenems. Most of the tested isolates were susceptible to tigecycline, and all of them were susceptible to colistin. Pulsed-field gel electrophoresis suggested that there had been several outbreaks of blaoxA-23-like and blaoxA-51-like-positive strains.

Conclusion: Carbapenem non-susceptible Acinetobacter isolates and OXA carbapenemase-producing isolates were prevalent. Dissemination of blaoxA-harboring isolates may make it difficult to treat infections due to carbapenem-resistant Acinetobacter spp. Further surveillance studies are required to prevent the spread of carbapenem resistance. (Korean J Clin Microbiol 2010;13:27-33)

Key Words: OXA carbapenemase, Carbapenem, Acinetobacter, Outbreak

\section{서 론}

Acinetobacter spp.는 포도당 비발효 호기성 그람음성 구간균 으로 폐렴, 요로감염, 심내막염, 창상감염 등 원내 감염을 잘 일 으키며 중환자실 및 병실 환경에서도 흔히 분리되고 있다[1].

근래 extended-spectrum $\beta$-lactamase (ESBL), AmpC $\beta$-lac-

Received 20 July, 2009, Revised 15 January, 2010

Accepted 18 February, 2010

Correspondence: Kyungwon Lee, Department of Laboratory Medicine and Research Institute of Bacterial Resistance, Yonsei University College of Medicine, 250, Seongsanno, Seodaemun-gu, Seoul 120-752, Korea. (Tel) 82-2-2228-2446, (Fax) 82-2-313-0908, (E-mail) leekcp@ yuhs.ac tamase 등의 효소를 생성하는 다제 내성 Acinetobacter spp.의 증가로 인해 carbapenem의 사용이 증가하였고, 결국은 이 약제 에 내성인 균주가 증가되기 시작하였다. 국내 분리 세균의 내 성률 조사에 의하면 Acinetobacter spp.의 carbapenem 내성률은 2001년 6\%에서 2004년 17\%로 증가하였다[2,3].

Acinetobacter spp.의 carbapenem제 내성기전은 class B와 D 형 carbapenemase에 의한 항균제의 불활화가 가장 중요하다 [4]. Class B에 속하는 metallo- $\beta$-lactamase (MBL)는 $\mathrm{Zn}^{2+}$ 가 있 어야 효소활성을 나타내며, clavulanic acid나 tazobactam과 같 은 $\beta$-lactamase 억제제에 의해서도 활성이 저해되지 않는다. Class D형 $\beta$-lactamase는 oxacillinase로도 불리며, 이는 penicillin보다 oxacillin을 더 빠르게 분해하는 특성 때문에 붙여진 
이름이다[5]. 현재 121종의 class D형 $\beta$-lactamase가 발견되었 으며, 그 중 45종은 carbapenem 분해 능력을 가지고 있다[6]. 염기서열 분석 비교를 통해 8 개의 군으로 나눌 수 있으며, 4 개 의 군(OXA-23형, OXA-24형, OXA-51형 및 OXA-58)이 임상 환자에서 분리된 Acinetobacter spp.에서 발견되었다[6].

최근 OXA형 carbapenemase를 생성하는 Acinetobacter spp. 가 유럽, 아시아 등 전 세계적으로 자주 보고되고 있고, 특히 OXA-23을 생성하는 Acinetobacter baumannii의 집단발생이 보 고된 바 있다[7-9].

2005년 Héritier 등은 OXA-51형 유전자가 A. baumannii에 내 재적으로 존재하고 있음을 보고하였고[9], Turton 등은 OXA-51 형 유전자 상부에 ISAbal이 삽입될 경우, 이들 유전자를 발현 시켜 carbapenem에 대한 $\mathrm{MIC}$ 를 증가시킬 수 있음을 보고하였 다[10]. 그러나 OXA형 carbapenemase의 종류와 ISAbal의 carbapenem 내성 발현에 미치는 영향에 대하여는 아직 적은 수의 보고만 있고, 국내 분리주에서의 현황에 대한 보고는 2005년도 분리균주를 대상으로 한 연구가 유일하다[11].

이에 본 연구에서는 서울과 경기도에 소재하는 2차와 3 차 병 원 환자에서 분리된 Acinetobacter spp.를 대상으로 carbapenem 내성 양상, $\mathrm{MBL}$ 과 $\mathrm{OXA}$ 형 carbapenemase 생성과 분자역학적 성상을 규명하고자 하였다.

\section{재료 및 방법}

\section{1. 대상 세균}

2006년 5월부터 11 월까지 서울 북서부, 북동부, 남서부 지역 과 경기지역에 위치한 4 개 병원 환자로부터 중복 분리주를 제 외한 429주의 Acinetobacter spp.를 수집하였다. 균종 동정은 전
통적인 생화학적 방법, Vitek $2 \mathrm{GN}$ 혹은 ID $32 \mathrm{GN}$ system (bioMerieux, Marcy-l'Etoile, France)를 이용하였다.

\section{2. 항균제 감수성 시험}

항균제 감수성은 CLSI 디스크 확산법 또는 Vitek 2 AST-N022 (bioMerieux)로 시험하였고, 일부 균주(171주)는 CLSI 한천희 석법으로 확인하였다[12]. 시험 항균제는 ceftazidime (GlaxoSmithKline, Greenford, UK), cefepime (Bristol-Myers Squibb, Princeton, NJ, USA), imipenem (Merck/Sharp \& Dohme, Rahway, NJ, USA), meropenem (Sumitomo, Tokyo, Japan), tigecycline (Wyeth, Madison, NY, USA)과 colistin (CJ제약, 서울, 대한민국)을 사용하였다. 항균제 감수성 시험의 정도 관리를 위하여 Escherichia coli ATCC 25922와 Pseudomonas aeruginosa ATCC 27853를 사용하였다.

\section{Carbapenem 내성 기전 규명}

Carbapenemase 생성 선별 시험은 carbapenem에 감수성이 저 하된 139주에서 imipenem 디스크를 이용한 Hodge 변법으로 carbapenemase 생성을, imipenem-EDTA double disk synergy 시험과 $\mathrm{MBL}$ 다중 $\mathrm{PCR}$ 시험으로 $\mathrm{MBL}$ 생성을 선별하였다 $[13,14]$.

OXA carbapenemase 생성 균주를 검출하기 위해서 imipenem 비감수성 139주와 감수성 균주 일부(32주)를 임의로 선택 하여 총 171주를 대상으로 시험하였다. bla $a_{\mathrm{OXA}-23}, b l a_{\mathrm{OXA}-24}$,

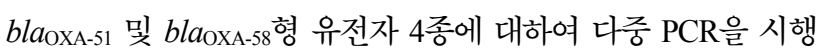
후 염기서열을 분석하였다(Table 1) [10,15].

OXA형 carbapenemase 내성 유전자가 검출된 균주를 대상으 로 ISAbal-F와 OXA-23-R 또는 OXA-51-R 시발체를 이용한

Table 1. Primers used for detection and sequencing of the metallo- $\beta$-lactamase, OXA carbapenemase, and ISAbal genes

\begin{tabular}{|c|c|c|c|}
\hline Target & Primer name & Primer sequence $\left(5^{\prime}\right.$ to $\left.3^{\prime}\right)$ & Reference \\
\hline \multirow[t]{2}{*}{$b l a_{\text {VIM-like }}$} & VIM-F & GAT GGT GTT TGG TCG CAT A & {$[14]$} \\
\hline & VIM-R & CGA ATG CGC AGC ACC AG & \\
\hline \multirow[t]{2}{*}{$b l a_{\mathrm{IMP}-\mathrm{like}}$} & IMP-F & GGA ATA GAG TGG CTT AAY TCT C & {$[14]$} \\
\hline & IMP-R & CCA AAC YAC TAS GTT ATC T & \\
\hline \multirow[t]{2}{*}{ bla $a_{\text {SIM-like }}$} & SIM-F & TAC AAG GGA TTC GGC ATC G & {$[14]$} \\
\hline & SIM-R & TAA TGG CCT GTT CCC ATG TG & \\
\hline \multirow[t]{3}{*}{ IS $A b a 1$} & ISAbal-F & CAC GAA TGC AGA AGT TG & [10] \\
\hline & ISAbal-R & CGA CGA ATA CTA TGA CAC & \\
\hline & ISAbalend-F & CAT TGA GAT GTG TCA TAG (Sequencing only) & \\
\hline \multirow[t]{2}{*}{ bla $a_{\text {OXA-23-like }}$} & OXA-23-F & GAT CGG ATT GGA GAA CCA GA & [15] \\
\hline & OXA-23-R & ATT TCT GAC CGC ATT TCC AT & \\
\hline \multirow[t]{2}{*}{ bla $a_{\text {OXA-24-like }}$} & OXA-24-F & GG T TAG TTG GCC CCC TTA AA & [15] \\
\hline & OXA-24-R & AGT TGA GCG AAA AGG GGA TT & \\
\hline \multirow[t]{2}{*}{ bla $a_{\text {OXA-51-like }}$} & OXA-51-F & TAA TGC TTT GAT CGG CCT TG & [15] \\
\hline & OXA-51-R & TGG ATT GCA CTT CAT CTT GG & \\
\hline \multirow[t]{2}{*}{$b l a_{\text {OXA- } 58}$} & OXA-58-F & AAG TAT TGG GGC TTG TGC TG & [15] \\
\hline & OXA-58-R & CCC CTC TGC GCT CTA CAT AC & \\
\hline
\end{tabular}


$\mathrm{PCR}$ 로 ISAbal의 존재를 확인하였다[10].

OXA형 carbapenemase 활성시험은 OXA형 carbapenemase 생성 균주를 LB broth에 18시간 배양 후 sonicator로 파쇄하고 $4^{\circ} \mathrm{C}$ 에서 $12,000 \mathrm{rpm}$ 으로 10 분간 원심분리 후 상청액을 사용하 였다. 효소활성은 $30^{\circ} \mathrm{C}$ 에서 $100 \mu \mathrm{M} \quad \beta$-lactam 제제(50 mM phosphate buffer, $\mathrm{pH}$ 7.0)를 UV-1601PC spectrophotometer (Shimadzu Corp., Tokyo, Japan)로 측정하였다. 사용된 파장은 benzylpenicillin (Sigma, St. Louis, MO, USA)은 $235 \mathrm{~nm}$, imipenem과 meropenem은 $297 \mathrm{~nm}$ 이었다. 단백질 정량은 protein assay (Bio-Rad, Hercules, CA, USA)를 제조사의 방법에 따라 시행하였다.

\section{Carbapenemase 생성 균주의 분자역학적 성상 분석을 위한 pulsed-field gel electrophoresis (PFGE)}

Carbapenemase 생성 균주들을 LB broth $5 \mathrm{~mL}$ 에 접종하고 18 시간 배양한 균주를 low-melting agarose (InCert Agarose, FMC Bioproducts, Rockland, Me, USA)에 넣어 굳히고 SmaI 제한효
소(Takara, Kyoto, Japan)로 처리하였다. CHEF DR II (Bio-Rad) 에 넣고 $6 \mathrm{~V}$ 에서 시작 3 초, 마지막 10 초의 switch time 조건으 로 20시간 전기영동하였다. Ethidium bromide $0.5 \mu \mathrm{L} / \mathrm{mL}$ 로 30 분간 염색한 후 UVIband/Map software (UVItech Ltd., Cambridge, UK)로 분자역학적 성상을 분석하였다.

\section{결 과}

\section{Acinetobacter spp.의 imipenem 내성률}

각 병원에서 분리된 Acinetobacter spp.의 imipenem 비감수성 률은 병원에 따라 상이하여 서울 지역의 A병원은 51\% (39/77), B병원은 $14 \%$ (26/191), C병원은 $67 \%$ (68/102), 경기지역의 D병 원은 $10 \%$ (6/59)이었다(Table 2). 전체 429균주 중 139주(32\%) 가 imipenem에 비감수성이었다. MBL생성 imipenem-EDTA double disk synergy 시험 양성 균주는 15 주였다. A병원에서 VIM-2 생성 2주와 SIM-1 생성 4주, B병원, C병원 및 경기지역 에 위치한 D병원에서 IMP-1 생성 균주가 각각 7주, 1 주 및 1 주

Table 2. Characteristics of OXA carbapenemase-producing Acinetobacter spp. by hospitals

\begin{tabular}{|c|c|c|c|c|c|c|c|c|c|c|}
\hline Hospital & $\begin{array}{l}\text { No. of } \\
\text { isolates }\end{array}$ & $\begin{array}{c}\text { No. of } \\
\text { IMP-NS, } \\
\text { PCR tested }\end{array}$ & $\begin{array}{c}\text { No. of } \\
\text { IMP-S, } \\
\text { PCR tested }\end{array}$ & $\begin{array}{l}\text { bla } a_{\mathrm{OXA}-51} \\
\text { alleles }\end{array}$ & $b^{b l a} a_{\mathrm{IMP}-1}$ & $b l a_{\mathrm{VIM}-2}$ & bla $_{\mathrm{SIM}-1}$ & 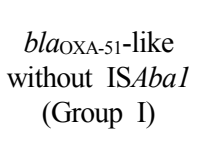 & $\begin{array}{l}b l_{\text {OXA-51-like }} \\
\text { with IS } A b a 1 \\
\text { (Group II) }\end{array}$ & $\begin{array}{l}\text { bla }_{\text {OXA-51-like }} \\
\text { with } \\
\text { bla }_{\text {OXA-23-like }} \\
\text { (Group III) }\end{array}$ \\
\hline \multirow[t]{2}{*}{ A } & \multirow[t]{2}{*}{77} & \multirow[t]{2}{*}{39} & \multirow[t]{2}{*}{10} & Pos (40) & - & - & - & 5 & 34 & 1 \\
\hline & & & & Neg (9) & 0 & 2 & 4 & - & - & - \\
\hline \multirow[t]{2}{*}{ B } & \multirow[t]{2}{*}{191} & \multirow[t]{2}{*}{26} & \multirow[t]{2}{*}{10} & Pos (29) & - & - & - & 28 & 1 & 0 \\
\hline & & & & Neg (7) & 7 & 0 & 0 & - & - & - \\
\hline \multirow[t]{2}{*}{$\mathrm{C}$} & \multirow[t]{2}{*}{102} & \multirow[t]{2}{*}{68} & \multirow[t]{2}{*}{7} & Pos (73) & - & - & - & 13 & 39 & 21 \\
\hline & & & & Neg (2) & 1 & 0 & 0 & - & - & - \\
\hline \multirow[t]{2}{*}{ D } & \multirow[t]{2}{*}{59} & \multirow[t]{2}{*}{6} & \multirow[t]{2}{*}{5} & Pos (9) & - & - & - & 5 & 1 & 3 \\
\hline & & & & Neg (2) & 1 & 0 & 0 & - & - & - \\
\hline \multirow[t]{2}{*}{ Total } & \multirow[t]{2}{*}{429} & \multirow[t]{2}{*}{139} & \multirow[t]{2}{*}{32} & Pos (151) & - & - & - & 51 & 75 & 25 \\
\hline & & & & Neg (20) & 9 & 2 & 4 & - & - & - \\
\hline
\end{tabular}

Abbreviations: IMP-NS, imipenem non-susceptible; IMP-S, imipenem susceptible; Pos, positive; Neg, negative.

Table 3. Antimicrobial susceptibility of blaxA-51-like-carrying Acinetobacter spp. isolates with or without ISAbal

\begin{tabular}{|c|c|c|c|c|c|c|c|c|c|}
\hline \multirow{2}{*}{$\begin{array}{l}\text { Antimicrobial } \\
\text { agent }\end{array}$} & \multicolumn{3}{|c|}{ 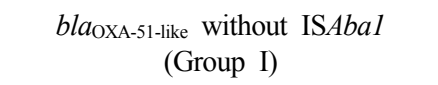 } & \multicolumn{3}{|c|}{$\begin{array}{c}\text { bla }_{\text {OXA-51-like with ISAbal }} \\
\text { (Group II) }\end{array}$} & \multicolumn{3}{|c|}{$\begin{array}{l}b l a_{\text {OXA-51-like }} \text { and } b l a_{\text {OXA-23-like }} \\
\text { with ISAbal (Group III) }\end{array}$} \\
\hline & $\begin{array}{c}\mathrm{MIC}(\mu \mathrm{g} / \mathrm{mL}) \\
\text { range } / \% \\
\text { non-susceptible }\end{array}$ & $\mathrm{MIC}_{50}$ & $\mathrm{MIC}_{90}$ & $\begin{array}{c}\mathrm{MIC}(\mu \mathrm{g} / \mathrm{mL}) \\
\text { range } / \% \\
\text { non-susceptible }\end{array}$ & $\mathrm{MIC}_{50}$ & $\mathrm{MIC}_{90}$ & $\begin{array}{c}\mathrm{MIC}(\mu \mathrm{g} / \mathrm{mL}) \\
\text { range } / \% \\
\text { non-susceptible }\end{array}$ & $\mathrm{MIC}_{50}$ & $\mathrm{MIC}_{90}$ \\
\hline Imipenem & $0.25 \sim 8 / 25$ & 4 & 8 & $2 \sim 16 / 99$ & 8 & 8 & $8 \sim 64 / 100$ & 16 & 32 \\
\hline Meropenem & $0.25 \sim 64 / 74$ & 8 & 16 & $4 \sim 128 / 99$ & 16 & 32 & $16 \sim 64 / 100$ & 32 & 64 \\
\hline Ceftazidime & $2 \sim>128 / 90$ & 128 & $>128$ & $64 \sim>128 / 100$ & 128 & $>128$ & $128 \sim>128 / 100$ & 128 & $>128$ \\
\hline Cefepime & $4 \sim>128 / 94$ & 32 & 128 & $16 \sim>128 / 100$ & 32 & $>128$ & $32 \sim>128 / 100$ & 128 & $>128$ \\
\hline Tigecycline & $0.25 \sim 4 / 6$ & 2 & 2 & $0.5 \sim 4 / 11$ & 2 & 4 & $1 \sim 2 / 0$ & 2 & 2 \\
\hline Colistin & $0.5 \sim 2 / 0$ & 1 & 2 & $0.5 \sim 2 / 0$ & 1 & 1 & $1 \sim 2 / 0$ & 2 & 2 \\
\hline
\end{tabular}


분리되었다. MBL 생성 균주 15 주는 모두 bla $a_{\mathrm{OXA}-51}$ 형 유전자 음성주였다(Table 2).

\section{OXA형 carbapenemase 생성 균주 및 ISAba1 보유 균주의 비율}

Acinetobacter spp. 171주(비감수성 139주, 감수성 32주) 중 bla $_{\text {OXA-51 }}$ 형 유전자 양성은 151 주였다. ISAbal 음성 blaXA-51형 유전자 양성주(group I)는 51주, ISAbal 양성 bla OXA-51형 유전 자 양성주(group II)는 75주, ISAbal, bla OXA-51 형 및 bla OXA-23 형 유전자가 동시에 양성인 균주(group III)는 25주였다(Table 2). 병원별로는 group I이 B병원에서 78\% (28/36)로 가장 흔하였 다. Group II는 A병원과 C병원 분리주에서 각각 $69 \%$ (34/49)와 $52 \%$ (39주/75주)로 높았고 B병원과 D병원은 각각 3\% (1주/36 주)와 $9 \%$ (1주/11주)에 불과하였다. Group III는 C병원과 D병 원에서 각각 $28 \%$ ( 21 주 $/ 75$ 주)와 $27 \%$ (3주/11주)로 높았고 다른 병원은 $2 \%$ 및 $0 \%$ 였다. bla $a_{\mathrm{OXA}-24}$ 형 및 bla $a_{\mathrm{OXA}-58}$ 형 양성균주는

Table 4. Hydrolytic activities (relative \%) of various OXA-carbapenemase-producing strains

\begin{tabular}{|c|c|c|c|}
\hline $\begin{array}{c}\text { Strain } \\
\text { (Group) }\end{array}$ & $\begin{array}{c}\text { K19, } \\
\text { bla } a_{\mathrm{OXA}-51-\text { like }} \\
\text { without IS } A b a 1 \\
\text { (Group I) }\end{array}$ & $\begin{array}{c}\mathrm{K} 28, \\
\text { bla } \\
\text { with ISAbal-like } \\
\text { (Group II) }\end{array}$ & $\begin{array}{c}\mathrm{K} 106, \\
\text { bla } a_{\mathrm{OXA}-51-\mathrm{like}} \\
\text { and bla } a_{\mathrm{OXA}-23-\mathrm{like}} \\
\text { with ISAbal } \\
\text { (Group III) }\end{array}$ \\
\hline Penicillin & 100 & 100 & 100 \\
\hline Oxacillin & $<1$ & 25 & 19 \\
\hline Cephalothin & 62 & 55 & 35 \\
\hline Imipenem & 1 & 3 & 2 \\
\hline Meropenem & $<1$ & 1 & 1 \\
\hline
\end{tabular}

검출되지 않았다.

\section{OXA형 carbapenemase 생성 균주의 항균제 감수성}

Group I에 대한 imipenem과 meropenem의 MIC 범위는 각각 $0.25 \sim 8 \mu \mathrm{g} / \mathrm{mL}$ 와 $0.25 \sim 64 \mu \mathrm{g} / \mathrm{mL}$ 이었고, group II는 각각 2 $16 \mu \mathrm{g} / \mathrm{mL}$ 와 4 128 $\mu \mathrm{g} / \mathrm{mL}$ 이었다(Table 3). 한편 group III에 대한 imipenem과 meropenem의 MIC 범위는 각각 $8 \sim 64 \mu \mathrm{g} /$ $\mathrm{mL}$ 와 $16 \sim 64 \mu \mathrm{g} / \mathrm{mL}$ 이었다. Imipenem과 meropenem에 대한 비감수성률은 group I에서 각각 $25 \%$ 와 $74 \%$, group II에서는 두 항균제 모두에서 $99 \%$, 그리고 group III에서는 두 항균제 모두 에서 $100 \%$ 였다. Group I에 비해 ISAbal 양성군인 group II, III 에서 imipenem에 대한 비감수성률은 각각 $74 \%$ 와 $75 \%$ 증가하 였다.

Tigecycline에 대해서는 대부분 균주가 감수성이었으며, colistin에 대해서는 모든 균주가 감수성이었다(Table 3).

\section{OXA형 carbapenemase의 내성 유전자 분석}

$b l a_{0 X \mathrm{XA}-51}$ 형과 $b l a_{\mathrm{OXA}-23}$ 형 유전자 양성 균주를 각각 6 주 임의 를 선택하여 정확한 유전자형을 결정하고자 염기서열을 분석 하였다. 12주 모두 ISAbal 양성이었으며, 전자 6주 중 4주는 $b l a_{0 \times A-83}$ 이었고, 2 주는 $b l a_{0 \times A-66}$ 과 유사한 분석결과를 나타내었 다. 후자 6 주는 모두 $b l a_{\mathrm{OXA}-23}$ 이었다.

\section{OXA형 carbapenemase에 의한 $\beta$-lactam 항균제의 가수분해 양상}

Group I, II 및 III 균주에서 각 군당 1 주씩을 선택하여 $\beta$ lactam 항균제에 대한 가수분해 양상을 시험하였다. OXA-23형 과 OXA-51형 효소생성 K106 균주(group III)와 ISAbal 양성

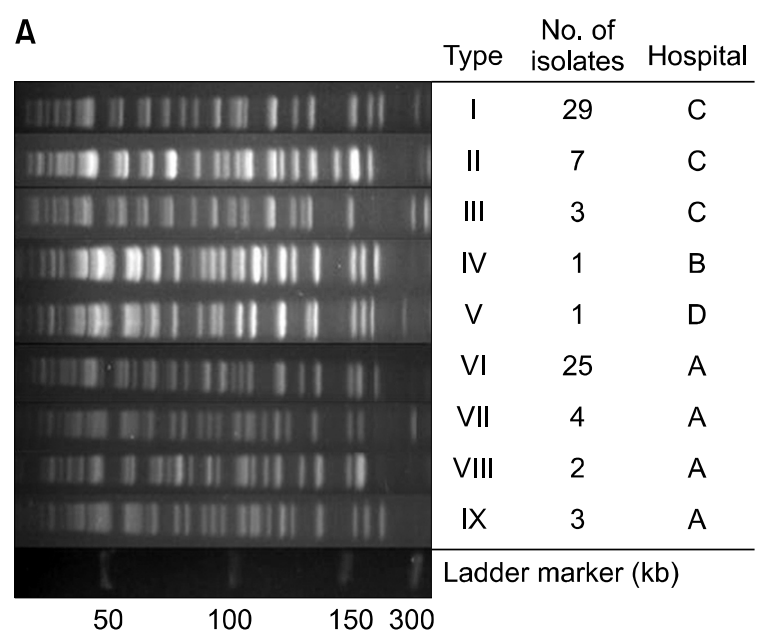

B

\begin{tabular}{|c|c|c|c|}
\hline & Type & $\begin{array}{c}\text { No. of } \\
\text { isolates }\end{array}$ & Hospital \\
\hline 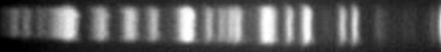 & $\mathrm{I}-1$ & 19 & C \\
\hline IIII $1 \mathrm{mI} \mathrm{Dill|} \mathrm{III}$ if & $1-2$ & 2 & C \\
\hline [11 101111 111011 0 & $\|$ & 1 & D \\
\hline 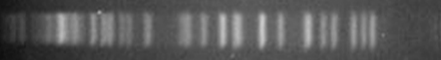 & III-1 & 1 & $\mathrm{D}$ \\
\hline 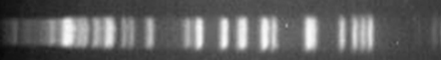 & III-2 & 1 & $\mathrm{D}$ \\
\hline IIIII HIII ITII & IV & 1 & A \\
\hline $18=9$ & Ladd & $\operatorname{ser}(\mathrm{kk}$ & \\
\hline
\end{tabular}

Fig. 1. Pulsed-field gel electrophoresis (PFGE) patterns of SmaI-restricted genomic DNA of Acinetobacter spp. isolates. (A) Isolates having

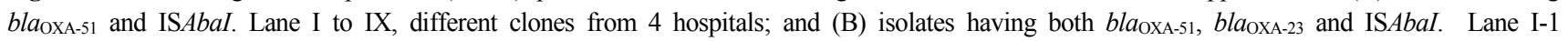
to IV, different clones from 4 hospitals; Molecular size (ladder marker) is given in kilobases. 
OXA-51형 효소 생성 K28 (group II) 균주가 ISAbal 음성 OXA-51형 효소 생성 K19 (group I)보다 oxacillin에 강한 분해 활성을 보였고, imipenem 및 meropenem에 대해서도 상대적인 활성도가 높았다(Table 4).

\section{ISAba1 양성 OXA-51형 carbapenemase 생성 균주(Group II)의 PFGE 성상}

OXA-51형 유전자가 양성인 75균주의 PFGE를 시행하여 비 교한 결과, 9 가지 형이 관찰되었다(Fig. 1A). C병원 분리 39주 는 3 가지 형, $\mathrm{A}$ 병원 분리 34 주는 4 가지 형이었으며, $\mathrm{B}$ 와 $\mathrm{D}$ 병 원 분리 각 1 주는 상기 병원과 다른 $\mathrm{IV}$ 형과 $\mathrm{V}$ 형이었다. C병원 과 $\mathrm{A}$ 병원 분리주 중에는 각각 I형과 VI형이 가장 많아서 동일 균주에 의한 집단발생이 흔함을 추정할 수 있었다.

\section{ISAba1 양성 OXA-23형과 OXA-51형 carbapenemase 생성 균주(Group III)의 PFGE 성상과 집단발생}

OXA-23형 carbapenemase 생성 균주는 25주였는데 A병원에 서 1주, $\mathrm{C}$ 병원에서 21주 및 $\mathrm{D}$ 병원에서 3주가 분리되었다(Fig. 1B). 이들 균주의 PFGE 성상은 병원에 따라 달랐다. 즉, $\mathrm{A}$ 병원 분리 1주는 IV형, $\mathrm{D}$ 병원에서 분리된 3주는 II와 III형이었다. 반 면에, C병원에서 분리된 21주는 모두 I형으로 동일 균주에 의 한 집단발생으로 판단되었고, 11 주 $(52 \%, 11$ 주/21주)가 중환자 실 환자에서 분리되었다.

\section{고 찰}

본 연구에서는 국내 임상환자에서 분리되는 Acinetobacter spp.의 OXA 형 carbapenemase 생성 균주의 비율을 조사하고, 국 내 전파상황, OXA형 carbapenemase 내성 유전자의 종류 및 내 성 유전자 보유 균주의 분자역학적 성상을 규명하고자 하였다.

Acinetobacter spp.의 imipenem 비감수성률은 병원마다 달라 서 $\mathrm{D}$ 병원이 $10 \%$ 로 가장 낮았으며, $\mathrm{A}$ 병원 $51 \%, \mathrm{~B}$ 병원 $14 \%, \mathrm{C}$ 병원 $67 \%$ 였다(Table 2). B병원과 C병원의 병상수는 약 800 병 상으로 비슷하였지만 비감수성률은 4 배나 차이를 보였으며, 이 는 병원 내 정착 세균의 원내 감염 확산의 차이가 있을 것으로 생각되었다. Carbapenem 내성률은 A병원은 $38 \%$ 로 타병원의 내성률(4 22\%)보다 현저히 높았는데, 이는 상대적으로 중환 자 및 암환자 등 장기입원 환자가 많은 병원 특성을 반영한 것 으로 생각되었다. 국내 분리 균주의 내성률 자료와 비교하였을 때 2004년 Korean Nationwide Surveillance of Antimicrobial Resistance (KONSAR) 조사연구에서 전국 병원 분리주의 내성 률은 $17 \%$ 였으며, 이는 C병원의 내성률과 비슷하였다[2].

본 연구에서 4개 병원에서 분리된 Acinetobacter spp. 171주 중 151 주가 $b l a_{\text {OXA-51 }}$ 형 유전자 양성이었고, 그 중에는 $b l a_{0 X A-51}$ 형 유전자와 ISAbal 동시 양성인 균주(Group II)가 75주
(75/151, 49.7\%)로 가장 많았다(Table 2). 이들의 비율은 병원에 따라 달랐는데 carbapenem 비감수성률이 높은 $\mathrm{A}$ 병원과 $\mathrm{C}$ 병원 에서 각각 $85 \%, 52 \%$ 로 가장 높았다. 이는 특정 병원 내 집단발 생 가능성을 시사하는 것으로 판단된다. 2005년도 분리 imipenem 내성 Acinetobacter spp.을 대상으로 시행한 KONSAR 연 구에서는 144 주 중 105 주(74.3\%)에서 bla $a_{\text {OAA }}$ 영 유전자 양성이 었고, 그 중 47주(44.8\%)가 bla $a_{\text {OXA-23 }}$ 형이었다[11]. 2006년 분리 균주가 대상인 본 연구에서 $b l a_{\mathrm{OXA}}$ 형 유전자 양성률은 $88.3 \%$ (151주/171주)로 KONSAR 연구결과보다 높았고 bla $a_{\text {OXA-23 }}$ 형 유 전자 양성률은 $16.5 \%$ (25주/151주)로 낮았다. 이 역시 특정 병 원 내 group II 균주의 집단발생 때문인 것으로 판단되었다.

Merkier 등은 OXA-51은 모든 A. baumannii에 존재한다고 하 였으며 Acinetobacter haemolyticus, Acinetobacter genomic species 10 또는 Acinetobacter lwofffii에서는 음성 결과를 보였다고 했으며 OXA-51 자체가 carbapenem에 내성을 나타내는 것인지 는 불확실하다고 하였다[16]. 본 연구에서 MBL 생성 균주 15 주는 모두 OXA-51이 존재하지 않았고, 다른 국외연구와 마찬 가지로 이 균주들은 non-baumannii Acinetobacter spp.의 가능 성이 크다고 판단되었다. 다른 연구 결과도 OXA-51이 아닌 OXA-58 또는 OXA-23이 존재해야 carbapenem에 내성을 나타 낸다고 하였으며 ISAbal이 bla $a_{\mathrm{OXA}-51}$ 의 상부에 존재해야 내성을 나타낸다고 하였다[17,18].

$b l a_{\text {OXA-51-like }}$ 양성 균주의 ISAbal 존재 유무에 따른 항균제 감 수성 시험에서 Acinetobacter spp.의 ceftazidime, cefepime, tigecycline 및 colistin에 대한 내성률은 ISAbal 음성군(Group I)과 양성군(Group II)에서 모두 비슷하였다(Table 3). 그러나 imipenem과 meropenem의 MIC 범위는 Group II 균주에서 각각 2 $16 \mu \mathrm{g} / \mathrm{mL}$ 와 4 128 $\mu \mathrm{g} / \mathrm{mL}$ 로 group I 균주보다 2 8배 높았으 며, imipenem과 meropenem에 대한 비감수성률이 모두 $99 \%$ 로 group I 균주보다 높았다. 이러한 결과는 ISAbal 양성인 Acinetobacter의 carbapenem MIC가 더 높다는 Turton 등의 보 고와 일치하였다[10]. bla $a_{\mathrm{OXA}-23}$ 형 유전자 양성균주(Group III)에 대한 imipenem과 meropenem의 $\mathrm{MIC}_{90}$ 은 각각 $32 \mu \mathrm{g} / \mathrm{mL}$ 및 64 $\mu \mathrm{g} / \mathrm{mL}$ 로 Group II의 $8 \mu \mathrm{g} / \mathrm{mL}$ 및 $32 \mu \mathrm{g} / \mathrm{mL}$ 보다 각각 4 배와 2 배 높았으며, imipenem, meropenem, ceftazidime 및 cefepime 에 대한 감수성 균주는 없었다. 이 결과는 carbapenem에 대한 내성에 OXA-23이 OXA-51보다 더 기여한다는 보고와 일치하 는 소견이었다[15]. 항균제들에 대한 가수분해 시험결과 group I에 비해 group II와 group III 균주가 oxacillin, imipenem 및 meropenem에 높은 가수분해 능력을 보였다. 이 가수분해 결과 는 각 군에 대한 항균제 내성률과 상관관계가 있는 것으로 판 단하였다(Table 4). 최근에 개발된 약제인 tigecycline과 colistin 에는 대부분 혹은 모두 감수성이어서 OXA carbapenemase를 가지고 있는 다제내성 Acinetobacter spp. 치료에 이들 약제가 유용할 것으로 생각되었다. 
근래 OXA carbapenemase 생성 균주에 의한 집단발생이 국 내외에서 보고된 바 있다. 본 연구에서도 서울지역 한 병원에 서 분리된 $b l a_{\text {OXA-23 }}$ 형 유전자 양성 균주는 모두 같은 PFGE 성 상을 보였다. 또한 $b l a_{\mathrm{OXA}-51}$ 과 ISAbal 동시 양성(Group II) 균 주는 서울지역 두 개 병원에서 집단발생하였음을 알 수 있었 다.

결론적으로 본 연구 대상인 4개 병원에서 Acinetobacter spp. 의 carbapenem 내성률은 다양하였고 OXA carbapenemase 생성 균주가 매우 흔하였으며 이들에 의한 병원 내 집단발생 역시 흔함을 추정할 수 있었다.

\section{참 고 문 헌}

1. Bergogne-Bérézin E and Towner KJ. Acinetobacter spp. as nosocomial pathogens: microbiological, clinical, and epidemiological features. Clin Microbiol Rev 1996;9:148-65.

2. Lee K, Lim CH, Cho JH, Lee WG, Uh Y, Kim HJ, et al. High prevalence of ceftazidime-resistant Klebsiella pneumoniae and increase of imipenem-resistant Pseudomonas aeruginosa and Acinetobacter spp. in Korea: a KONSAR program in 2004. Yonsei Med J 2006;47:634-45.

3. Lee K, Jang SJ, Lee HJ, Ryoo N, Kim M, Hong SG, et al. Increasing prevalence of vancomycin-resistant Enterococcus faecium, expanded-spectrum cephalosporin-resistant Klebsiella pneumoniae, and imipenem-resistant Pseudomonas aeruginosa in Korea: KONSAR study in 2001. J Korean Med Sci 2004;19:8-14.

4. Poirel L and Nordmann P. Carbapenem resistance in Acinetobacter baumannii: mechanisms and epidemiology. Clin Microbiol Infect 2006;12:826-36.

5. Bush K, Jacoby GA, Medeiros AA. A functional classification scheme for $\beta$-lactamases and its correlation with molecular structure. Antimicrob Agents Chemother 1995;39:1211-33.

6. Walther-Rasmussen J and Høoiby N. OXA-type carbapenemases. J Antimicrob Chemother 2006;57:373-83.

7. Naas T, Levy M, Hirschauer C, Marchandin H, Nordmann P. Outbreak of carbapenem-resistant Acinetobacter baumannii producing the carbapenemase OXA-23 in a tertiary care hospital of
Papeete, French Polynesia. J Clin Microbiol 2005;43:4826-9.

8. Jeon BC, Jeong SH, Bae IK, Kwon SB, Lee K, Young D, et al. Investigation of a nosocomial outbreak of imipenem-resistant Acinetobacter baumannii producing the OXA-23 $\beta$-lactamase in Korea. J Clin Microbiol 2005;43:2241-5.

9. Héritier C, Dubouix A, Poirel L, Marty N, Nordmann P. A nosocomial outbreak of Acinetobacter baumannii isolates expressing the carbapenem-hydrolysing oxacillinase OXA-58. J Antimicrob Chemother 2005;55:115-8.

10. Turton JF, Ward ME, Woodford N, Kaufmann ME, Pike R, Livermore DM, et al. The role of ISAbal in expression of OXA carbapenemase genes in Acinetobacter baumannii. FEMS Microbiol Lett 2006;258:72-7.

11. Lee K, Kim MN, Choi TY, Cho SE, Lee S, Whang DH, et al. Wide dissemination of OXA-type carbapenemases in clinical Acinetobacter spp. isolates from South Korea. Int J Antimicrob Agents 2009;33:520-4.

12. Clinical and Laboratory Standards Institute. Performance Standards for Antimicrobial Susceptibility Testing. Sixteenth ed. Wayne, PA: CLSI, 2006.

13. Lee K, Chong Y, Shin HB, Kim YA, Yong D, Yum JH. Modified Hodge and EDTA-disk synergy tests to screen metallo- $\beta$ lactamase-producing strains of Pseudomonas and Acinetobacter species. Clin Microbiol Infect 2001;7:88-91.

14. Lee K, Yum JH, Yong D, Lee HM, Kim HD, Docquier JD, et al. Novel acquired metallo- $\beta$-lactamase gene, bla $a_{\mathrm{SIM}-1}$, in a class 1 integron from Acinetobacter baumannii clinical isolates from Korea. Antimicrob Agents Chemother 2005;49:4485-91.

15. Woodford N, Ellington MJ, Coelho JM, Turton JF, Ward ME, Brown S, et al. Multiplex PCR for genes encoding prevalent OXA carbapenemases in Acinetobacter spp. Int J Antimicrob Agents 2006;27:351-3.

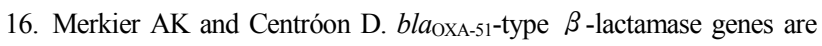
ubiquitous and vary within a strain in Acinetobacter baumannii. Int J Antimicrob Agents 2006;28:110-3.

17. Tsakris A, Ikonomidis A, Pournaras S, Spanakis N, Markogiannakis A. Carriage of OXA-58 but not of OXA-51 $\beta$-lactamase gene correlates with carbapenem resistance in Acinetobacter baumannii. J Antimicrob Chemother 2006;58:1097-9.

18. Segal H, Garny S, Elisha BG. Is ISAba- 1 customized for Acinetobacter? FEMS Microbiol Lett 2005;243:425-9. 
=국문초록=

\title{
2006년 서울과 경기지역 4개 병원에서 분리된 Carbapenem 내성 Acinetobacter spp.의 내성 기전과 분자역학
}

\author{
${ }^{1}$ 고려대학교 의과대학 진단검사의학교실, ${ }^{2}$ 결핵연구원, ${ }^{3}$ 동의대학교 자연과학대학 임상병리학과, \\ ${ }^{4}$ 연세대학교 의과대학 진단검사의학교실, ${ }^{5}$ 세균내성연구소

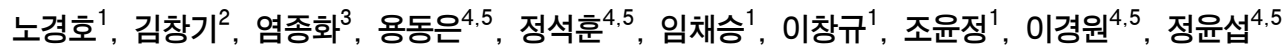

배경: 최근 carbapenem을 포함한 다약제 내성 Acinetobacter spp.가 증가하고 있어 심각한 문제가 되고 있다. 본 연구에서 는 국내 4개 병원에서 분리되는 Acinetobacter spp.의 항균제 내성 양상과 carbapenem 내성 기전 및 분자역학적 성상을 규명하고자 하였다.

방법: 2006년 5월에서 11월까지 서울의 세 지역과 경기의 한 지역에 위치한 4개 중대형병원 환자에서 분리된 Acinetobacter spp. 균주를 수집하였다. CLSI 디스크 확산법과 한천희석법으로 항균제 감수성을 시험하였고, PCR 검사로 metallo- $\beta$-lactamase와 OXA형 carbapenemase 생성균을 검출하였다. OXA형과 ISAbal의 유무에 따른 carbapenem 내성과 가수분해능을 비교하였고, OXA형 carbapenemase 생성균의 염색체 DNA의 pulsed-field gel electrophoresis (PFGE) 성상을 분석하였다.

결과: Acinetobacter spp.의 carbapenem 비감수성률은 $10 \sim 67 \%$ 로 일부 병원에서 이미 높았다. OXA carbapenemase를 생성 하는 151주는 ISAb1이 없는 bla $a_{\mathrm{OXA}-51}$ 형 51주, ISAbal 동시양성인 $b l a_{\mathrm{OXA}-51}$ 형 75주, ISAba1, bla $a_{\mathrm{OXA}-51}$ 과 $b l a_{\mathrm{OXA}-23}$ 동시 양성 인 균주 25주로 구성되어 있었다. bla $a_{\mathrm{OXA}-51}$ 형 중 ISAbal이 존재하는 균주가 carbapenem MIC가 높았으며, $b l a_{\mathrm{OXA}-51}$ 단독 존재보다 $b l a_{\mathrm{OXA}-23}$ 동시 존재 균주가 carbapenem $\mathrm{MIC}$ 가 높았다. 가수분해 활성도 측정에서도 $b l a_{\mathrm{OXA}-51}$ 형 중 ISAbal이 존 재하는 균주와 $b l a_{\mathrm{OXA}-23}$ 가 동시 존재 균주가 oxacillin에 강한 분해활성을 보였고, carbapenem에 대해서도 상대적인 활성도 가 높았다 Tigecycline에는 대부분의 시험균주가, colistin에는 시험 균주 모두가 감수성이었다. PFGE분석으로 $b l a_{\mathrm{OXA}-23}$ 형 과 $b l a_{\mathrm{OXA}-51}$ 형 유전자 양성 균주에 의한 집단발생이 흔함을 알 수 있었다.

결론: 국내 분리 Acinetobacter spp. 중에 carbapenem 내성균주와 OXA형 carbapenemase 생성 균주는 매우 흔하였고 병원 내 집단 발생이 종종 있음을 추정할 수 있었다. OXA형 carbapenemase 생성 균주의 확산은 carbapenem 내성 Acinetobacter spp.에 의한 감염증 치료를 어렵게 할 것이므로 이에 대한 향후 대책이 시급할 것으로 생각한다. [대한임상미생물학회지 2010;13:27-33]

교신저자 : 이경원, 120-752, 서울시 서대문구 성산로 250

연세대학교 의과대학 진단검사의학교실, 세균내성연구소

Tel: 02-2228-2446, Fax: 02-313-0908

E-mail: leekcp@yuhs.ac 